\title{
Assessing the Long-Term Effect on Sales and CSR of a Nutrition Marketing Strategy in the Retailing Environment
}

\author{
Benedetta Grandi ${ }^{1}$, Maria Grazia Cardinali ${ }^{1}$, Silvia Bellini ${ }^{1}$ \\ ${ }^{1}$ Department of Economics and Management, University of Parma, Parma, Italy \\ Correspondence: Benedetta Grandi, Department of Economics and Management, University of Parma, Parma, \\ 43123 Via Kennedy 6, Italy.
}

Received: February 23, 2019

Accepted: March 25, 2019

Online Published: October 25, 2019

doi:10.5539/ibr.v12n11p94

URL: https://doi.org/10.5539/ibr.v12n11p94

\begin{abstract}
The present work aims to implement a 'healthy checkout' in a real retailing environment in order to demonstrate that this kind of intervention can be a win-win strategy for both shoppers and retailers in a long-term perspective. A field experiment has been conducted in five stores belonging to a leading Italian Retailer in the north of Italy, where all the unhealthy products have been removed from the checkouts. Both sales analysis and shoppers attitudes towards the intervention have been studied. Sales data have been analyzed for the 'healthy checkout stores' vs 'traditional checkout stores', and customers have been interviewed at the end of the shopping trip five months after the implementation. Our findings show that developing a healthy checkout can have a positive impact on sales, retailer's reputation in terms of perceived CSR, and loyalty to the store. The present work provides some interesting results about the long-term effect of an in-store marketing strategy that aims to promote health among customers.
\end{abstract}

Keywords: nudging, retailing, health, checkout

\section{Introduction}

Unhealthy snacks were found to be an important contributor to the spread of overweight and obesity and to chronical diseases (Duffey and Popkin, 2011). However, retailers and manufacturers have tried to promote snacks, and consequently unhealthy diets, by playing on the impulsive nature on their purchase (Luomala et al., 2018) and placing them in prominent locations inside the store, such as the checkout (van Kleef et al., 2012). Along the path to purchase, the checkout represents an area where all shoppers must pass through when they go shopping (Horsley et al., 2014) and for this reason, it is considered one of the most powerful location that can promote impulsive purchases (Wang and Lang, 2015).

In the light of the changes that are occurring in both consumption and purchasing behaviours, characterized by an increasing interest towards healthy aspects of food and also snacks (Nielsen, 2014), it is reasonable to wonder whether persisting in the promotion of unhealthy snacks could affect retailers in terms of customers' satisfaction, brand image and reputation.

The present work aims to implement and test a 'healthy checkout' in a real retailing environment in order to understand the long-term impact of this kind of intervention on sales and retailer's image. This because every retailer's strategy can be measured in terms of sales and impact on company's reputation. Furthermore, we wanted to check the consistency between what shoppers state and how they actually behave.

By implementing this strategy, we want to fill several gaps. First, we want to enrich the literature about the strategies developed in grocery setting. To the authors' knowledge, only few experiments have been conducted in a real environment and most of them have been conducted in setting other than grocery stores, such as hospital canteens and train stations (van Kleef et al., 2012; Kroese et al., 2016). However, because grocery stores are the main location where food purchases are carried out, a deeper focus on this environment is needed (Adam et al., 2017). Furthermore, the long term effect of in-store marketing strategies in grocery environment has almost been assessed through sales data analysis of healthy versus unhealthy products (Kroese et al., 2016; Sigurdsson et al., 2014). No studies have tried to demonstrate the impact of in-store health promotion strategies on brand image and loyalty.

In order to fill those gaps, the present work is organized as follow. First, we describe the importance of the 
strategy, we discuss the literature about the antecedents of CSR and loyalty to the store and we posit our hypothesis. Second, we describe the intervention and we present the two studies. Finally, we discuss the results and we draw some general conclusions.

\section{Literature Review}

Placing healthy products at the checkout is one of the strategies named as 'nudging'. Nudging reshapes the environment in which shoppers take their decisions by changing the presentation of options to consumers and making them more appealing, without removing options, changing economic incentives or constraining shoppers' liberty of choice (Thaler and Sustein, 2008). Nudging it is argue to be a powerful strategy (Adam et al., 2017) that can be implemented to promote health and the literature recognizes several types of nudging, respectively named 'Attention', 'Interest' and 'Action' (Cadario and Chandon, 2017). Specifically, the intervention proposed in the present work refers to 'Attention'. 'Attention' concerns the information given to shoppers: it can be in the form of "descriptive nutritional labelling", which provides a calories count or information about other nutrients; or in the form of "evaluative nutritional labelling", which typically provides nutritional information, and also helps consumers interpret it by colour coding or special symbols or marks. Finally, information can be provided in the form of 'augmented" labelling, which draws attention to the healthiest options and helps consumers categorize food options according to their healthiness. In addition to the information, 'attention' nudging technique aims to influence the visibility of food on shelves. The interventions made so far have focused their attention on developing single interventions, while it has been argued that the combination of different stimuli can be a more powerful strategy in helping shoppers adopting healthy behaviours (van Kleef et al., 2012). Only altering accessibility and visibility could not be enough, since customers must be aware of the 'prime' in order to behave in line the cue (Salmon et al., 2014).

Information is one of the most important variables in healthy food related choices. In fact, nutritional profile for each product is provided through NIP, placed on the back of the packages, or, in general, in places other than visible ones (Hamlin and McNeill, 2016). The huge amount of information and its difficult accessibility are the two main barriers that prevent the proper use of nutritional information. But acting only on the communication lever can be counterproductive if products still remain exposed in a way that fails helping customers easily identifying healthy products inside the store (Lugli, 2015). Thus, we propose an intervention in which both accessibility and availability and 'augmented' nutritional information are provided in a real setting.

Despite the importance of the theme, to the authors' knowledge, only few experiments have been conducted in a real environment and most of them have been tested in settings other than grocery stores. Van Kleef et.al tested the effect of availability and accessibility of healthy and unhealthy food products at the checkout in hospital canteen (van Kleef et al., 2012). They conducted one laboratory study and one field study and they found out that availability more than accessibility can lead to an increasing number of healthy choices made and an increase in sales of healthy products. In addition, Kroese et al., discussed the benefits of implementing healthy checkout in a train station (Kroese et al., 2016). Sigurdsson et al., implemented a healthy checkout in two stores in Norwey, where they promoted two kinds of products and they demonstrated that placing healthy products in prominent locations can lead to a substantial impact on sales of these products at the expense of unhealthy ones (Sigurdsson et al., 2014). Finally, Chapman and Ogden conducted two field experiments in a University canteen setting. In particular, they focused their attention on two aspects of the environment: the location of food (close to or away from the checkout) and the availability of food. They found that the healthy food sales increased when healthy products are positioned away from the checkouts but that this increase did not persist after the intervention. Then, they found that the effect depends on the characteristics of the products selected (Chapman and Odgen, 2012).

Every retailer's strategy can have an impact on sales and company's reputation. Considering sales data, it is arguable that promoting such strategy could be beneficial for both customers and retailers. Customers who are looking for healthy products, can easily identify healthy products inside the store (Nielsen, 2014) and then, they will react positively to the strategy and will buy more healthy products. Due to the higher price and margins of healthy snacks compared to unhealthy ones (Lugli, 2015), we expect an increase in the sales of healthy checkouts compared to traditional ones, which still promote chocolate and candies. Thus, we posit that:

\section{H1. Placing healthy snacks at the checkout can be beneficial for the retailer, in terms of sales}

Apart from sales, a major long term-effect of promoting healthy eating is on retailer's reputation. Is has been recognized that the food industry has a "major impact on what people eat" and that "nine out of ten consumers do most of their shopping at a supermarket". This emphasises that "the food industry has a corporate social responsibility to promote healthy eating" (Jones et al., 2005). Corporate social responsibility (CSR) reflects the 
company's status and activities with respect to its societal obligations (Brown and Dacin, 1997). Being perceived as a socially responsible company can have a positive impact on levels of trust and loyalty among consumers (Cole, 2017). Among the factors found to be the antecedents of perceived CSR, can be cited branding, reputation building, and communications (Stanaland et al., 2011). Previous studies applied the concept of CSR to both nutritional information and healthful food contexts. Several authors found that providing healthy foods and nutritional information is considered as a healthy eating CSR initiative (Jones et al., 2005; Lee and Heo, 2009). However, less attention has been given to the effects of corporate social responsibility's (CSR) actions on consumers and their perceptions of the firm and on the relationships between healthy eating initiatives and perceived CSR. Some authors have measured that relationship in setting other than grocery store, such as restaurant (Lee and Heo, 2009). So far, the CSR in the grocery retailing was assessed through the information that companies provide to the stakeholders on the website about their social and environmental commitment and not through in-store marketing strategies (Jones et al., 2005). Thus, we believe that placing healthy products at the checkout and communicating them using easily processable nutritional information could have an impact on perceived CSR and that perceived CSR could affect loyalty to the retailer. Thus, we posit the following hypothesis:

\section{H2. Providing healthy products at the checkout positively influences consumers'perceptions of CSR}

H3. Providing attractive and informative communication at the checkout positively influences consumers' perceptions of CSR

H4. Increasing consumers' perceptions of corporate social responsibility positively influences the loyalty to the store

\section{Method}

\subsection{Procedure - The Development of the Healthy Checkout}

Thanks to the collaboration of an Italian leading chain, we initially implemented healthy checkouts in five supermarkets in the north of Italy. All the stores were located in suburb areas, were medium sized, and belonged to Every Day Low Price format.

In all the stores considered, unhealthy snacks were removed from all the checkouts of each store and were displayed away from that area on a sideboard, as tested in a previous study (Chapman and Ogden, 2012). At the checkouts, they were all replaced by a selection of healthy products (mix of fresh fruit, dried fruit, dried fruit bars, nuts and smoothies). The selection of the healthy items was based on the overall nutritional profile of each product. In particular, we used a Nutrition Information System (NIS) which takes into account the content of energy, saturated fat, sodium, sugars, fibres, proteins and the proportion of fruit, vegetables, nuts and legumes content, and assign a scores, that goes from $1 / 2$ to 5 (Hamlin and McNeill, 2016), to each product analysed (Health Star Rating System). Lower scores mean that products have low nutritional values, while high scores mean that they have good nutritional values. The products displayed at the checkouts achieved a score higher than the minimum acceptable score set in accordance with the retailer (minimum score $=2$ ). For each product, the corresponding score has been communicated with stars symbol. Finally, the communication placed on the top of the checkouts shelves gave information about the criterion used for the selection of the items and the meaning of the scores.

Several algorithms and FOP labels have been developed so far, but to the authors' knowledge, this seems to be the more complete one, since it takes into account the majority of the nutrients provided in the Nutrition Information Panel displayed on the back of the package of each product.

\subsection{Study 1: The Long Term Impact of Healthy Checkout on Sales}

Measures. Thanks to the collaboration of the Retailer, we had the possibility to access sales data of healthy checkout in the five stores were this implementation was made (experimental stores), and sales data of five stores in which confectionary was still displayed at the checkouts (control stores). All the stores considered are similar in terms of store dimension, total turnover and shoppers' characteristics and this allows the comparison. In order to compare the results, we considered the incidence (percentage) of checkouts sales on the total turnover of packaged food within the stores considered (experimental versus control stores) during a 26-week period after the implementation (from May 2016 to November 2016). A t-test was conducted in order to assess the statistical difference between the incidence of healthy and unhealthy checkout on total sales during this period. Data were analysed using SPSS 24 statistical software.

Findings. We found a statically significant difference between the two measures considered, by conducting a $\mathrm{t}$-test. The result allowed us to reject the null hypothesis of equality of the means (average incidence of healthy 
and unhealthy checkout sales on total turnover) at a level of .05 (Mean healthy checkout $=1.6785, \mathrm{Mean}_{\text {unhealthy }}$ checkout $=1.5783, \mathrm{t}-2.105, \mathrm{p}<.05$ ). This means that the incidence of healthy checkout is significantly higher than the incidence of unhealthy checkout over the period considered (26 weeks). The result confirms our hypothesis: displaying healthy products at the checkout can be a way to improve retailer's profits for at least two reasons. First, the price of these products is higher than candies and chocolate and, consequently, their margin. Secondly, these products are more able to meet consumers' needs since healthiness is an aspect that consumers take into account also when choosing snacks (Nielsen, 2014).

\subsection{Study 2: The Long Term Impact of Healthy Checkout on CSR and Loyalty to the Store}

Study 2 aims to assess the impact of the intervention proposed, and in particular, the perception of the assortment and the communication on Corporate Social Responsibility and of CSR on loyalty to the store. The total sample considered was composed by 310 shoppers, interviewed in three store in the cities of Parma and Modena (northern part of Italy). After removing 6 participant due to incomplete questionnaires, we had a sample of 304 shoppers. Among them, 47 bought a healthy snack from the checkout, while 257 did not buy it but they, at least, noticed the new checkout and could answer the questions about communication and assortment.

Measures. Since we managed both assortment and nutritional communication, perception about the assortment (in terms of novelty and healthiness of the products) and of the communication (attractiveness and informative aspects) were measured as antecedents of perceived CSR (Zhou and Wong 2004). Two 7-points items measured the novelty of the products displayed ('The products offered at the checkout are new for me', 'This is a shelf packed with new and attractive products'), while two 7-points items measured the perception of healthiness of the products displayed ('I think that the products displayed are healthy', 'This is a shelf display packed with healthy snacks'). Both variables were based on the scale developed by van Kleef et al. in 2012. The attitude towards the communication was assessed measuring both the informative aspect using a 7-points item ('This communication helps me to get more information') and its perceived ability to influence behaviours through two 7-points items, ('The communication is effective', and 'I think that this kind of communication can influence individual's choices'). The items used come from the scale developed by Moreau et al. in 2001. CSR was measured by three 7-points items ('This retailer cares about my health status', 'This retailer is much more attentive to my health status than others', 'This retailer contributes to people's well-being'). The scale was based on the one developed by Brown and Dacin and adapted for the purpose of the study (Brown and Dacin, 1997). In the same way, Loyalty to the store was measured trough three 7-points items ('I prefer to always shop at this grocery store', 'I am willing to make an effort to shop at my favourite grocery store', 'This point of sales is my first choice'). This last scale comes from the one developed by Ailawadi et al. in 2001. Data were analysed using SmartPLS package.

Results and analysis. Perception towards the advertising was measured through different dimensions (informative aspects and attractiveness), and we applied a partial aggregation, so these two dimensions are used as representative items for the main construct (communication perception). This is justified by the high correlation between the items of each dimension found in the sample analysed. Firstly, the measurement model was run in order to check the convergent and discriminant validity. We found that convergent validity requirement was met, since all the Cronbach's alpha were higher than .70 and the AVE scores were higher than .70 for each construct (Tables 1 ).

Table 1. Convergent validity - AVE and Cronbach's alpha

\begin{tabular}{lccc}
\hline & Cronbach's Alpha & Composite Reliability & Average Variance Extracted (AVE) \\
\cline { 2 - 4 } CSR & 0.848 & 0.908 & 0.766 \\
Communication & 0.882 & 0.927 & 0.808 \\
Healthiness of the products & 0.894 & 0.950 & 0.904 \\
Loyalty & 0.817 & 0.891 & 0.733 \\
Novelty of the products & 0.714 & 0.875 & 0.777 \\
\hline
\end{tabular}

Furthermore, all the cross loadings for each construct were found to be higher than .75, as shown in Table 2 . 
Table 2. Convergent validity - Cross loadings

\begin{tabular}{|c|c|c|c|c|c|}
\hline & Communication & CSR & Healthiness & Novelty & Loyalty \\
\hline Comm_1 & 0.885 & 0.144 & 0.194 & 0.195 & 0.009 \\
\hline Comm_2 & 0.932 & 0.202 & 0.267 & 0.258 & 0.042 \\
\hline Comm_3 & 0.879 & 0.173 & 0.257 & 0.324 & 0.049 \\
\hline CSR_1 & 0.204 & 0.870 & 0.249 & 0.202 & 0.314 \\
\hline CSR_2 & 0.191 & 0.841 & 0.247 & 0.250 & 0.256 \\
\hline CSR_3 & 0.131 & 0.914 & 0.318 & 0.265 & 0.400 \\
\hline DisplaY_Health_1 & 0.266 & 0.279 & 0.945 & 0.534 & 0.074 \\
\hline DisplaY_Health_2 & 0.249 & 0.315 & 0.957 & 0.540 & 0.065 \\
\hline Display_novelty_1 & 0.285 & 0.237 & 0.516 & 0.877 & 0.147 \\
\hline Display_novelty_3 & 0.229 & 0.246 & 0.481 & 0.886 & 0.204 \\
\hline Loyalty_1 & -0.016 & 0.272 & 0.072 & 0.136 & 0.883 \\
\hline Loyalty_2 & 0.049 & 0.395 & 0.115 & 0.223 & 0.915 \\
\hline Loyalty_3 & 0.060 & 0.273 & -0.023 & 0.135 & 0.764 \\
\hline
\end{tabular}

Discriminant validity, otherwise, indicates that the items actually measure their theoretical corresponding construct and not any other constructs. We found that the square root of the AVE for each construct was higher than its correlation with other constructs (Table 3 ).

Table 3. Discriminant validity

\begin{tabular}{lccccc}
\hline & CSR & Communication & Healthiness & Loyalty & Novelty \\
\cline { 2 - 6 } CSR & $\mathbf{0 . 8 7 5}$ & & & & \\
Communication & 0.195 & $\mathbf{0 . 8 9 9}$ & & & \\
Healthiness & 0.314 & 0.270 & $\mathbf{0 . 9 5 1}$ & & \\
Loyalty & 0.376 & 0.039 & 0.073 & $\mathbf{0 . 8 5 6}$ & $\mathbf{0 . 8 8 2}$ \\
Novelty & 0.274 & 0.291 & 0.565 & 0.200 & \\
\hline
\end{tabular}

Finally, Table 4 shows the structural model and levels of significance (t-values). Bootstrapping resampling served to test the level of significance of the path coefficients.

Table 4. Path coefficient - structural model

\begin{tabular}{lccc}
\hline & Path coefficients & T Statistics & P Values \\
\cline { 2 - 4 } CSR -> Loyalty & 0.376 & 8.200 & 0.000 \\
Communication_-> CSR & 0.101 & 1.760 & 0.079 \\
Healthiness -> CSR & 0.218 & 3.483 & 0.001 \\
Novelty -> CSR & 0.121 & 1.973 & 0.049 \\
\hline
\end{tabular}

Findings. By looking at the output, we can assess that all the hypothesis were met. No matter whether the shoppers bought or not a healthy snack from the checkout, the mere presence can influence the perceived CSR, in terms of promotion of small dietary changes inside the store. Specifically, the perception toward the communication used was found to influence the perceived CSR at a significant level ( $\mathrm{p}<.10)$. In the same way, both perceived healthiness and novelty of the products proposed were found to affect CSR at the significant level $\mathrm{p}<.05$. The stronger correlation was found between CSR and Loyalty to the store $(.376, \mathrm{p}<.001)$. CSR may depend on several different variables, such as the quality of the entire assortment (specifically, fish, meat, fruit and vegetables), the freshness of the products, the way fruit and vegetables are presented inside the store, the value for money and so on. However, even if the effect is small, there is a significant impact of the healthy checkout of the perceived CSR. 


\section{General Conclusion and Managerial Implications}

Our research wanted to test the long-term effect of a strategy that aims to promote health inside grocery stores and fill several gaps in the extant literature. First of all, the healthy checkout we tested is the first example run by an Italian retail chain as a way to promote health among customers. Furthermore, many authors have argued that there is a lack of contributions which assess the long-term effect of such a strategy (Cadario and Chandon 2017; Adriaanse et al. 2014). The majority of the studies have focused their attention on the short-term effect of strategies which aim to promote health among customers, by conducting experiments and analysing the choice, without considering the fact that the effectiveness of the interventions might decrease overtime (Chapman and Odgen, 2012; Adriaanse et al. 2014; Wood and Neal 2016).

The long term effect is almost assessed through sales data analysis (Kroese et al., 2016; van Kleef et al., 2012; Chapman and Odgen, 2012), while no studies have tried to demonstrate the impact of these strategies on brand image and customers loyalty. In fact, by promoting health and by communicating retailer's efforts, customers can perceived it as socially responsible and improve the attitude towards the company (Piacentini et al., 2000). So far, the CSR in the grocery retailing has been assessed through the information that companies provide to the stakeholders on the website about their social and environmental commitment and not through in-store marketing strategies (Jones et al., 2005; Piacentini et al., 2000).

The results of our study allow us to assess that displaying healthy products at the checkout could be a way to improve retailers profits and perceived image. First, it has been argued that the price of the healthy products is higher than the price of candies and chocolate and, therefore, their margins. Furthermore, the fact that the sales of healthy checkout were significantly higher than the sales of traditional ones over a 26-weeks period, could suggest that shoppers appreciated the products and that they were willing to re-purchase them. Many authors argued that one of the main problems that discourages the selection and re-purchase of healthier products is, apart from the price, the taste, since unhealthy products are seen as something tasteful and gratifying, while healthy products as something tasteless and not enjoyable. However, by priming shoppers with 'healthy' cues it is possible to continuously tempt them buying healthier products and help them get used to the products promoted. Lugli, in 2015 argued that taste could be changed through repetitive purchases and consumption and that offering health cues could have a strong long-term effect on preferences (Lugli 2015).

Secondly, shoppers are increasing their interest towards the healthy aspects of food. For this reason, developing strategies that help shoppers making healthy choices without effort is seen as something valuable, that impact the perceived CSR and positively affect the loyalty to the store. Confectionery merchandising may represent an opportunity for retailers to brand themselves as health-oriented and exercise their sense of social responsibility. They can strengthen customer loyalty without necessarily damaging overall profits and find a way of differentiation in a competitive market.

\section{References}

Adam, A., Jensen, J. D., Sommer, I., \& Hansen, G. L. (2017). Does shelf space management intervention have an effect on calorie turnover at supermarkets? Journal of Retailing and Consumer Services, 34, 311-318. https://doi.org/10.1016/j.jretconser.2016.07.007

Adriaanse, M. A., Kroese, F. M., Gillebaart, M., \& De Ridder, D. T. D. (2014). Effortless inhibition: habit mediates the relation between self-control and unhealthy snack consumption. Frontiers in Psychology, 5. https://doi.org/10.3389/fpsyg.2014.00444

Ailawadi, K. L., Neslin, S. A., \& Gedenk, K. (2001). Pursuing the Value-Conscious Consumer: Store Brands Versus National Brand Promotions. Journal of Marketing, 65(1), 71-89. https://doi.org/10.1509/jmkg.65.1.71.18132

Brown, T. J., \& Dacin, P. A. (1997). The Company and the Product: Corporate Associations and Consumer Product Responses. Journal of Marketing, 61(1), 68. https://doi.org/10.2307/1252190

Romain, C., \& Pierre, C. (2017). Which Healthy Eating Nudges Work Best? A Meta-Analysis of Behavioral Interventions in Field Experiments. https://doi.org/10.2139/ssrn.3090829

Chapman, K., \& Ogden, J. (2012). Nudging Customers towards Healthier Choices: An Intervention in the University Canteen. Journal of Food Research, 1(2). https://doi.org/10.5539/jfr.v1n2p13

Cole, G. (2017). Increasing customer loyalty: the impact of corporate social responsibility and corporate image. Annals in Social Responsibility, 00-00. https://doi.org/10.1108/ASR-09-2017-0007

Duffey, K. J., \& Popkin, B. M. (2011). Energy Density, Portion Size, and Eating Occasions: Contributions to 
Increased Energy Intake in the United States, 1977-2006. PLoS Medicine, 8(6), e1001050. https://doi.org/10.1371/journal.pmed.1001050

Hamlin, R., \& McNeill, L. (2016). Does the Australasian "Health Star Rating" Front of Pack Nutritional Label System Work? Nutrients, 8(6), 327. https://doi.org/10.3390/nu8060327

Horsley, J. A., Absalom, K. A., Akiens, E. M., Dunk, R. J., \& Ferguson, A. M. (2014). The proportion of unhealthy foodstuffs children are exposed to at the checkout of convenience supermarkets. Public Health Nutrition, 17(11), 2453-2458. https://doi.org/10.1017/S1368980013003571

Jones, P., Comfort, D., \& Hillier, D. (2005). Corporate social responsibility and the UK's top ten retailers. International Journal of Retail \& Distribution Management, 33(12), 882-892. https://doi.org/10.1108/09590550510634611

Kroese, F. M., Marchiori, D. R., \& de Ridder, D. T. D. (2016). Nudging healthy food choices: a field experiment at the train station. Journal of Public Health, 38(2), e133-e137. https://doi.org/10.1093/pubmed/fdv096

Lee, S., \& Heo, C. Y. (2009). Corporate social responsibility and customer satisfaction among US publicly traded hotels and restaurants. International Journal of Hospitality Management, 28(4), 635-637. https://doi.org/10.1016/j.ijhm.2009.02.007

Lugli, G. (2015). Cibo, salute e business: neuroscienze e marketing nutrizionale (Prima edizione). Milano: Egea.

Luomala, H. T., Hellén, K., \& Jokitalo, M. (2018). Dieting, priming, food meanings and (un) healthy choices: When shoppers fall for pleasure. Journal of Retailing and Consumer Services, 41, 305-311. https://doi.org/10.1016/j.jretconser.2017.05.001

Moreau, C. P., Markman, A. B., \& Lehmann, D. R. (2001). "What Is It?" Categorization Flexibility and Consumers' Responses to Really New Products. Journal of Consumer Research, 27(4), 489-498. https://doi.org/10.1086/319623

Piacentini, M., MacFadyen, L., \& Eadie, D. (2000). Corporate social responsibility in food retailing. International Journal of Retail \& Distribution Management, 28(11), 459-469. https://doi.org/10.1108/09590550010356822

Salmon, S. J., Fennis, B. M., de Ridder, D. T. D., Adriaanse, M. A., \& de Vet, E. (2014). Health on impulse: When low self-control promotes healthy food choices. Health Psychology, 33(2), 103-109. https://doi.org/10.1037/a0031785

Sigurdsson, V., Larsen, N. M., \& Gunnarsson, D. (2014). Healthy food products at the point of purchase: An in-store experimental analysis: HEALTHY FOOD. Journal of Applied Behavior Analysis, 47(1), 151-154. https://doi.org/10.1002/jaba.91

Stanaland, A. J. S., Lwin, M. O., \& Murphy, P. E. (2011). Consumer Perceptions of the Antecedents and Consequences of Corporate Social Responsibility. Journal of Business Ethics, 102(1), 47-55. https://doi.org/10.1007/s10551-011-0904-z

Thaler \& Sustein. (2008). Nudge: improving decisions about health, wealth, and happiness. Choice Reviews Online, 46(02), 46-0977-46-0977. https://doi.org/10.5860/CHOICE.46-0977

van Kleef, E., Otten, K., \& van Trijp, H. C. (2012). Healthy snacks at the checkout counter: A lab and field study on the impact of shelf arrangement and assortment structure on consumer choices. BMC Public Health, 12(1). https://doi.org/10.1186/1471-2458-12-1072

Wang, S. C., \& Lang, M. (2015). The effects of special displays on shopping behavior. Journal of Retailing and Consumer Services, 23, 125-132. https://doi.org/10.1016/j.jretconser.2014.12.009

Wood, W., \& Neal, D. T. (2016). Healthy through habit: Interventions for initiating \& maintaining health behavior change. Behavioral Science \& Policy, 2(1), 71-83. https://doi.org/10.1353/bsp.2016.0008

Zhou, L., \& Wong, A. (2004). Consumer Impulse Buying and In-Store Stimuli in Chinese Supermarkets. Journal of International Consumer Marketing, 16(2), 37-53. https://doi.org/10.1300/J046v16n02_03

\section{Copyrights}

Copyright for this article is retained by the author(s), with first publication rights granted to the journal.

This is an open-access article distributed under the terms and conditions of the Creative Commons Attribution license (http://creativecommons.org/licenses/by/4.0/). 